\title{
Fe, recreación y turismo: el peregrino de Santa María de la Asunción Tepexoyuca, Ocoyoacac, Estado de México
}

Recibido: 31/08/2015 - Aceptado: 01/10/2015

\author{
Yesenia Janeth Reyes Reyes \\ Maribel Osorio García* \\ Universidad Autónoma del Estado de México
}

\section{Resumen}

El presente artículo tiene como objetivo analizar el ethos social de los peregrinos del pueblo de Santa María de la Asunción Tepexoyuca, particularmente en su recorrido anual al Santuario del Señor de Chalma, Estado de México, para comprender su sentido subjetivo y su conexión con la práctica turísticorecreativa. A partir de la fenomenología sociológica de Schütz y con base en el concepto del ethos de Lalive, se revisa el significado que tiene para aquéllos formar parte de esta peregrinación. Metodológicamente, se llevó a cabo un proceso de investigación cualitativa mediante entrevistas en profundidad que fueron examinadas con un modelo interpretativo de análisis de contenido. Los resultados permitieron distinguir dos tipos de ethos de los peregrinos que participan en este desplazamiento: uno tradicional, al que se le denominó inflexible, y el otro innovador, al que se le llamó flexible; este último es el que presenta un comportamiento recreativo articulado al ritual.

Palabras clave: Chalma, ethos, peregrinación, recreación, turismo religioso.

*Correo electrónico: maribelosorio2@gmail.com 


\title{
Faith, recreation and tourism: the pilgrim of Santa Maria de la Asuncion Tepexoyuca, Ocoyoacac, Estado de México
}

\author{
Yesenia Janeth Reyes Reyes \\ Maribel Osorio García* \\ Universidad Autónoma del Estado de México
}

\begin{abstract}
This work has the aim of analyzing the social ethos of pilgrims of the Santa María de la Asunción Tepexoyuca village, in particular their yearly pilgrimage to the Señor de Chalma sanctuary in the State of Mexico, to comprehend it's subjective meaning and it's connection to touristic and recreational activities. Based on Schütz's sociological phenomenology and on the concept of ethos of Lalive, the meaning of participating in the pilgrimage is reviewed. A qualitative research method was applied through in depth interviews whose outcome was interpreted with a content analysis model. The results allowed the identification of two ethos types of the pilgrims; one traditional type that was termed inflexible, and a second innovative one, termed flexible that represents a recreational structured attitude towards the ritual.
\end{abstract}

KEY worns: Chalma, ethos, pilgrimage, recreation, religious tourism.

*E-mail: maribelosorio2@gmail.com 


\section{Introducción}

El turismo religioso y el peregrinaje pueden entrar en discusión por los enfoques que se han prestado para definirlos. Podemos encontrar a Eade (1992, cit. en Sharpley, 2009), quien destaca que las actividades de turismo y peregrinaje son consideradas por compartir características similares respecto al uso de transporte, facilidades de alojamiento y otros servicios, mientras que los peregrinos participan también en el comportamiento "turístico", en actividades como la recreación y la compra de recuerdos. En este diálogo, Sharpley (2009) indica que si bien puede resultar seguro asumir que ciertos grupos de visitantes son motivados religiosamente, lo puede ser menos admitir que los otros, los visitantes seculares, no tienen alguna motivación o experiencia espiritual. Además menciona que la distinción entre peregrinos/turistas de patrimonio religioso y turistas seculares/turistas no religiosos es menos clara de lo que sugiere la literatura existente.

En general se reconoce que el turismo religioso como objeto de estudio es reciente, ya que con antelación se le tomaba como una expresión más del turismo cultural (Cànoves y Blanco, 2011; Martínez, 2009; Fernández, 2010), Así también, el peregrinaje ha quedado enmarcado en el turismo religioso, planteándose como un mismo fenómeno (Ruezga y Martínez, 2011), en el que se mueven masas humanas unidas por un mismo ideal. Para una distinción entre ambas manifestaciones se puede aludir que el turismo religioso se interpreta como aquel que se compone de patrones religiosos, culturales, espirituales y paisajísticos, que muchas veces interactúan en la intención y decisión de emprender un viaje (Aulet y Hakobyan, 2011), mientras que la peregrinación se define como un viaje realizado por motivos religiosos a un lugar que se considera sagrado, para efectuar allí determinados actos religiosos, de devoción y penitencia (Rebic, 1999). Entonces, el turismo religioso puede entenderse como la actividad que realizan los turistas al visitar templos o lugares de significado sagrado para determinada religión, siendo el lugar un destino más de su viaje, en tanto que en el peregrinaje se establece un santuario o un sitio sagrado como una meta que implica un ritual.

Dentro de las investigaciones que se han llevado a cabo en el ámbito turístico religioso y el peregrinaje, sobresalen las siguientes: Ruezga y Martínez (2011) mencionan que al peregrino se le puede clasificar como ocasional y 
Fe, recreación y turismo: el peregrino del pueblo de Santa María de la Asunción Tepexoyuca, Ocoyoacac, Estado de México

permanente, urbano y rural; y es este peregrinaje continuo de personas por el cual pretenden adquirir la gracia de la imagen o agradecer a esta. Autores como Aulet y Hakobyan (2011) concluyen que, para un peregrino, todo el camino de peregrinación está dirigido hacia el destino final que es el lugar sagrado donde se produce una expresión religiosa de su identidad y se realiza el culto sagrado; para el peregrino, las prácticas religiosas forman parte importante de todo el camino, considerado como algo serio, auténtico y legítimo.

En cuanto a la motivación y el desarrollo personal del desplazamiento, Cànoves y Blanco (2011) destacan que es difícil saber cómo el peregrino lleva a cabo la experiencia, la intensidad y el significado del peregrinaje, generalizando la motivación del viaje como algo meramente religioso, donde el peregrino adopta símbolos que aportan a su vivencia un sentido único. Respecto a esta razón de peregrinaje, Millán et al. (2010) subrayan un trasfondo en la motivación religiosa de los peregrinos, pues señalan que son estos quienes durante el viaje y principalmente en la estancia en el destino realizan actividades de carácter turístico.

Se observa entonces la carencia de profundidad en cuanto a un análisis cualitativo de las motivaciones por las que un peregrino forma parte de este ritual, el cual ayude a definir, subjetivamente hablando, el significado que tienen estos desplazamientos para las personas que, como se da por hecho, se basan en la fe y en la tradición que con el paso de los años les han sido inculcadas. Una investigación de este tipo permitirá ahondar en el conocimiento sobre si existe algún interés turístico-recreativo junto con el significado que tiene un ritual de peregrinaje.

El santuario del Señor de Chalma, en el Estado de México, México, de acuerdo con la clasificación de Juárez et al. (2012), es uno de importancia nacional, con una vasta afluencia de peregrinos, el cual recibe millones de creyentes al año que alaban y confirman la cantidad de milagros que la imagen del Cristo del santuario otorga a sus fieles.

La peregrinación que realiza el pueblo de Santa María de la Asunción Tepexoyuca, del municipio de Ocoyoacac, en el Estado de México, al santuario del Señor de Chalma se ha desarrollado desde mediados del siglo xix, y ha pasado de generación en generación, por lo que ahora constituye un elemento del 
patrimonio cultural de la comunidad. Además, es efectuada por una gran parte del pueblo, permitiendo que sea por todos conocida y establecida como un ritual de gran trascendencia.

Varios son los papeles que las personas desempeñan dentro de la peregrinación al santuario del Señor de Chalma, ya que ellos determinan el sentido y la motivación por el que asisten: hay quienes van por pagar una manda, por establecer un compromiso con la imagen sagrada, por acompañarla, por conocer cómo se realiza la peregrinación o por recrearse durante el trayecto y en el destino. Esta primera noción permite distinguir que hay diferentes motivaciones para asistir a la peregrinación, las cuales están vinculadas con las intenciones y elementos valorativos de las personas, por lo que la presente investigación tiene como objetivo analizar el ethos social de los peregrinos del pueblo de Santa María de la Asunción Tepexoyuca desde las dimensiones espacial, temporal y social, para comprender su sentido subjetivo y su conexión con la práctica turístico-recreativa.

A fin de alcanzar el mencionado objetivo, el artículo se estructura en tres apartados. En el primero se exponen las características referenciales sobre cómo se lleva a cabo la peregrinación por parte de la población de Santa María de la Asunción Tepexoyuca; en el segundo se integra el marco teórico-metodológico, donde se explica el concepto de ethos, el modelo de interpretación que se siguió y los métodos empleados para la investigación de campo; en el tercero se examinan las dimensiones temporal, social y espacial a partir del análisis de contenido aplicado, identificando el ethos del peregrino. Por último se incluyen algunos comentarios a manera de conclusiones.

\section{La peregrinación del pueblo de Tepexoyuca al santuario del Señor de Chalma}

La comunidad de Santa María de la Asunción Tepexoyuca se ubica al este del municipio de Ocoyoacac, en el Estado de México, y colinda con su cabecera municipal, por lo que su demarcación se difumina con respecto a ella (véase figura 1). El nombre de Santa María de la Asunción se debe a que ella es la santa patrona del pueblo, mientras que el nombre de Tepexoyuca proviene del náhuatl y significa "monte azul". 
Fe, recreación y turismo: el peregrino del pueblo de Santa María de la Asunción Tepexoyuca, Ocoyoacac, Estado de México

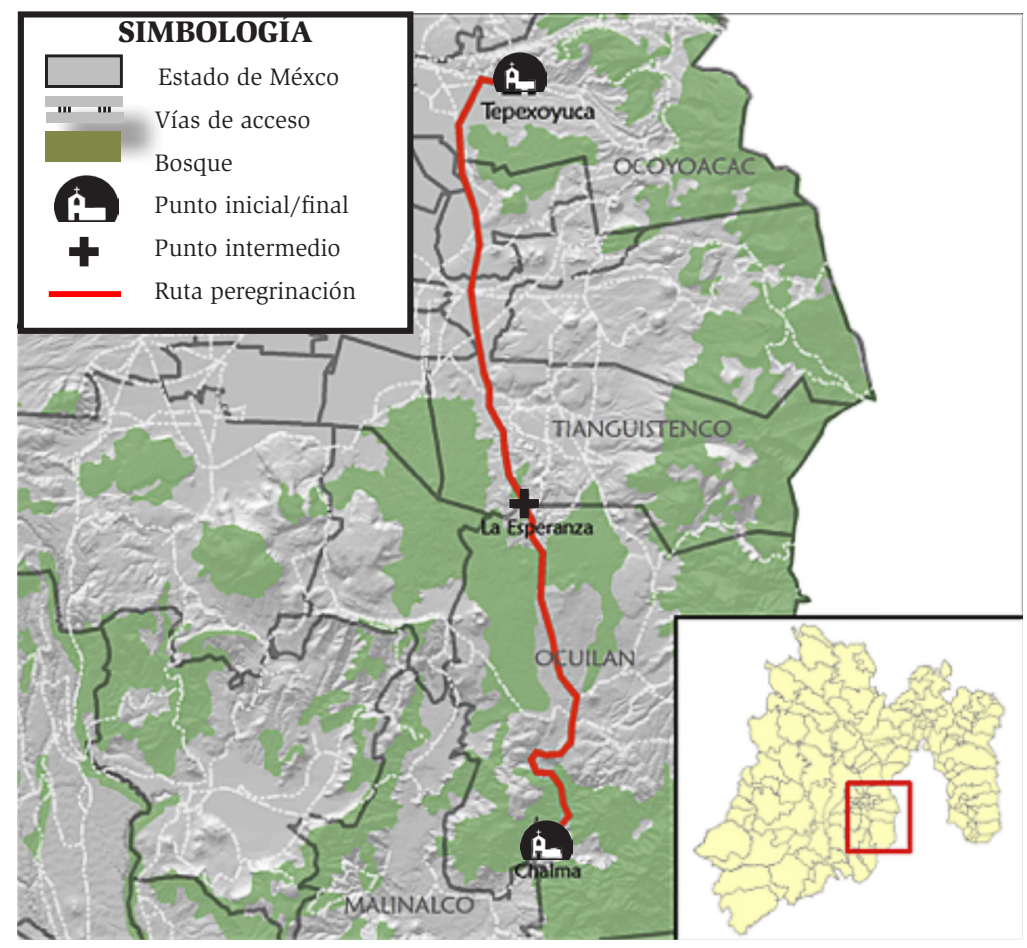

Fuente: Elaborado por el Dr. Héctor Hugo Regil García.

Figura 1. Localización de Santa María de la Asunción Tepexoyuca y el Santuario de Chalma, Estado de México, México

En cuanto a las características físicas, Tepexoyuca se encuentra rodeado de distintas elevaciones montañosas, las cuales están cubiertas por la principal zona boscosa de la comunidad. El uso de suelo del pueblo se divide en forestal y agropecuario. Cuenta con una caída de agua temporal, que desemboca en uno de los ríos que recorren el pueblo.

Con relación a sus características socioeconómicas, el Conteo de Población y Vivienda del Instituto Nacional de Estadística y Geografía (2010), en su estimación de 2012, reporta 61805 habitantes del municipio de Ocoyoacac, sin embargo, debido al crecimiento urbanizado de la cabecera municipal y la cercanía con el pueblo, no es posible tener un número exacto de personas pertenecientes a 
Tepexoyuca; gran parte de la población se dedicaba a la siembra de maíz y, en un porcentaje menor, a la de cebada y avena. El establecimiento de diversas empresas de carácter industrial y la creación de comercios independientes en el municipio han abierto ofertas de trabajo para la población, desplazando a la agricultura como principal fuente económica. Respecto a las condiciones de vivienda, $90 \%$ de la población cuenta con los servicios de agua potable, luz y drenaje, además de calles pavimentadas, de loza y alumbrado público.

El pueblo de Santa María de la Asunción Tepexoyuca se ha distinguido por ser mayoritariamente católico, y una gran cantidad de personas pertenecientes a la comunidad asisten a la peregrinación anual al santuario del Señor de Chalma, la cual tiene sus orígenes como una actividad comercial que se desarrollaba hacia el municipio de Tenancingo a mediados del siglo xIx, siendo los arrieros y comerciantes los que observaban el desplazamiento de peregrinos al santuario del Señor de Chalma. Estos movimientos dieron oportunidad de conocer sobre lo milagrosa que era esta imagen, interesando a la comunidad de Tepexoyuca a ir a visitarla, tras el ejemplo de uno de sus miembros que inició el recorrido con el propósito de agradecer un favor cumplido por parte del Señor de Chalma. A partir de entonces, personas de la comunidad se unieron para ir cada año al santuario, junto con otras del barrio vecino, Santiaguito, llevando en un principio estandartes o distintas imágenes que representaran su fe en la peregrinación.

A finales del siglo xix se hizo una colecta para comprar una imagen que se pudiera llevar todos los años al santuario: la imagen llamada "Señor de la Cañita” o "El Divino Salvador" ha sido llevada en la peregrinación desde entonces (véase figura 2); asimismo, años después, el barrio de Santiaguito adquirió su propia imagen de un tamaño menor, para que "acompañara” al Señor de la Cañita del pueblo de Tepexoyuca.

A principios del siglo xx, la peregrinación peligró por los movimientos revolucionarios, siendo bloqueado el camino hacia el santuario. Bajo la amenaza de hurtar las imágenes del Señor de la Cañita, los peregrinos se vieron obligados a sustituirlas por las alcancías de tales imágenes. En esa época, un señor de la comunidad, fiel a la Iglesia y a la imagen del Señor de la Cañita, decidió comprar una réplica pequeña, a nombre de una asociación religiosa, la cual acompañaba a las dos imágenes predecesoras al santuario del Señor de Chalma. Es a partir de entonces cuando se realiza la peregrinación con las tres imágenes del Señor de la Cañita. 
Fe, recreación y turismo: el peregrino del pueblo de Santa María de la Asunción Tepexoyuca, Ocoyoacac, Estado de México

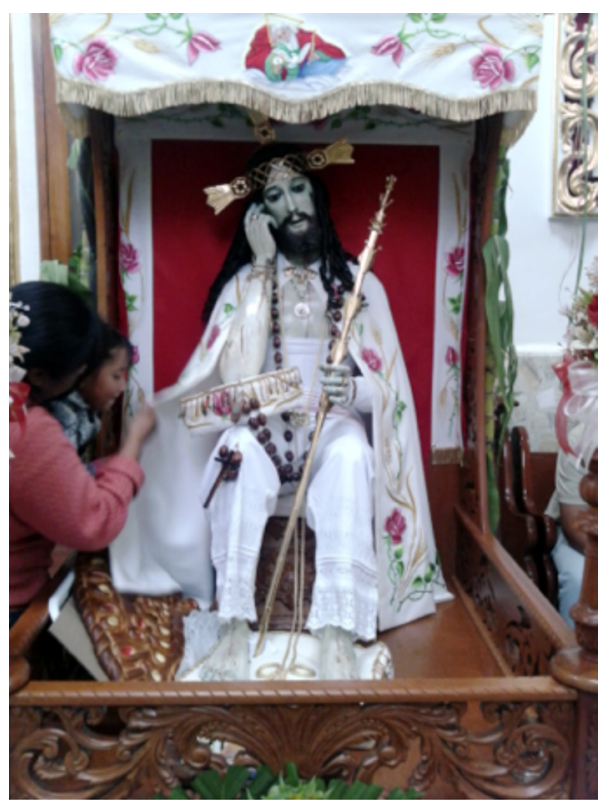

Fuente: Fotografía tomada durante la investigación de campo.

Figura 2. El Señor de la Cañita de Santa María de la Asunción Tepexoyuca

La peregrinación al santuario del Señor de Chalma se lleva a cabo del 2 al 10 de enero, llegando en un transcurso de día y medio al santuario, acampando en "el monte" en la localidad de La Esperanza, para arribar al templo el 3 de enero por la tarde. Durante siete días permanecen en la comunidad efectuando distintas actividades; el día 9 parten del templo de regreso a Santa María de la Asunción Tepexoyuca, descansando nuevamente en "el monte" durante la noche, para llegar la tarde del día siguiente a su pueblo de origen.

Los peregrinos de Santa María de la Asunción Tepexoyuca van a Chalma principalmente con el propósito de seguir una tradición que se ha preservado a lo largo de los años. Algunos de ellos asisten con el fin de acompañar a los denominados "mayordomos", personas encargadas de cuidar las imágenes durante un año, atendiendo a los compromisos que se presentan, ya sea en la peregrinación o en la celebración de la imagen. Los mayordomos van a dejar su cargo allá, a quienes ocuparán su puesto como encargados de las imágenes durante el año siguiente, por lo que familiares y amigos acompañan a estas 
mayordomías a lo largo del peregrinaje; un grupo de mayordomos hace las llamadas "asistencias" en descansos ya establecidos donde brindan alimentos y bebidas a quienes los acompañan.

Las mayordomías van a llevar al santuario del Señor de Chalma las limosnas juntadas en todo el pueblo alrededor del año que ha transcurrido. Con una parte de ellas se paga una misa en el santuario a favor del Señor de la Cañita el 6 de enero. Asimismo, los mayordomos discuten si es conveniente dejar en el santuario las limosnas reunidas a lo largo de la peregrinación o regresar con ellas para usarlas en el templo u ofrecerlas en el altar de la imagen.

Asimismo, hay peregrinos que van porque están en la lista de futuros mayordomos; suelen ser principalmente los que recibirán la mayordomía al siguiente año y acuden para "observar las costumbres": cómo se realiza todo el peregrinaje, las actividades llevadas a cabo antes de salir del pueblo, las visitas a los oratorios, la misa y las paradas que se hacen en distintos lugares.

La población asiste cada año a la peregrinación, pues esta tiene un sentido y significado profundo para cada persona. Se carece de un registro exacto del número de peregrinos que se desplazan, pero se calcula que se reúnen entre 2500 y 3 000, además de las familias de los mayordomos que van a dejar comida a cada uno de los descansos que se establecen a lo largo del trayecto. El hecho de que las imágenes del Señor de la Cañita sean consideradas milagrosas permite que las personas las acompañen durante el recorrido, ya que en su familia se les ha inculcado desde muy pequeños seguir con esta tradición. Entre los peregrinos hay quienes van a pagar mandas, además de otros que ven el peregrinaje como una manera de pedir ser favorecidos en alguna situación por la que están atravesando, colocando así su fervor en la imagen para llegar al templo junto con ella. El acto de fe que conlleva el peregrinaje permite también que las personas vayan a agradecer un año más de vida, así como los favores que se les hayan cumplido durante este periodo. La peregrinación es para algunos un modo de expresar su devoción hacia la imagen, buscando incluso ser perdonados por los pecados que hayan cometido.

Existen quienes forman parte de la peregrinación a fin de aprovechar el tiempo que tienen de vacaciones, conociéndola más de cerca y cómo se lleva a cabo, integrándose a una manifestación de su cultura. Otros solo asisten por curiosidad, al desear vivir la experiencia de lo que se hace a lo largo de los nueve días. 
Fe, recreación y turismo: el peregrino del pueblo de Santa María de la Asunción Tepexoyuca, Ocoyoacac, Estado de México

Durante la peregrinación las personas pueden incorporarse a los rezos y cantos que se realizan. Además pueden convivir con los miembros de la comunidad y los locales de los sitios donde se descansa, para comer algo de lo que ofrecen los mayordomos o la gente que vive ahí. La peregrinación permite que las personas que van con motivo de recreación conozcan más sobre los lugares por los que se va pasando, hasta llegar al santuario y formar parte de la ceremonia.

A lo largo de la estadía en Chalma, las personas normalmente asisten a misa los días que se encuentran ahí, y usan los servicios que brinda la localidad. La principal atracción, después de ir al templo y a las comidas que ofrecen los mayordomos, son los balnearios ubicados en Chalma, lo que constituye una motivación para el peregrino.

Es por ello que el desplazamiento de los pobladores a Chalma muestra diferentes significados derivados de las creencias, normas y valores que los estructuran, y que conforman los motivos por los cuales cada peregrino decide visitar el santuario. Dada esta perspectiva de análisis subjetivo, ahora se exponen las categorías teóricas de la presente investigación.

\section{Marco teórico-metodológico}

Las peregrinaciones se definen como desplazamientos que han sido realizados desde la Antigüedad y forman parte de un ritual; manifiestan la cultura y religión de los pueblos, siendo ambas elementos fundamentales del ser humano. Iracheta y Montes (2009) mencionan que los rituales permiten reafirmar la identidad social; el sentido de pertenencia a la comunidad se da en una relación pasado-actualidad, ancestros-herencia, que motiva a defender y fomentar las celebraciones religiosas porque ahí está la historia de su pueblo.

Este tipo de desplazamientos permite observar una serie de motivaciones por las que los peregrinos forman parte del ritual, las cuales poseen un carácter subjetivo, que se indaga mediante un proceso de investigación cualitativa, con base en un cuerpo teórico explicativo del comportamiento social, que ayuda a entender el sentido por el cual se lleva a cabo este peregrinaje.

Denzin y Lincoln (1994, cit. en Rodríguez, Gil y García, 1999) señalan que la investigación cualitativa es aquella que intenta explicar los fenómenos que se suscitan dentro de un contexto natural de acuerdo con los significados que tienen 
para las personas implicadas. La investigación cualitativa brinda distintos métodos, los cuales son utilizados para conocer la realidad; para esta investigación se ha considerado usar el de la fenomenología sociológica, donde Alfred Schütz (1995) menciona que la conciencia como punto de partida establece los significados y motivos de las cosas, así como los procesos de comprensión e interpretación, para dar respuesta a los comportamientos subjetivos. Según Schütz, los significados hacen referencia al modo en que los actores determinan qué aspectos del mundo social son importantes para ellos (Ritzer, 1993, p. 280). En la misma línea, Crespi (1997) conceptualiza el significado como cualquier representación del sí mismo y de la realidad, que no solamente refiere circunstancias congénitas de la vida individual, sino también de dimensiones psicológicas y de modelos socioculturales y normativos. El peregrino se observa como aquel que, pese a que sigue comportamientos en conjunto, atribuye de manera personal el significado, permitiendo entender por qué lo lleva a cabo. Es aquí donde las representaciones, valores y reglas adquieren vida propia.

Por lo anterior, la metodología cualitativa empleada en la presente investigación utilizó las técnicas de entrevista a profundidad y análisis de contenido. Las entrevistas a profundidad permitieron extraer un relato autobiográfico del sujeto, cuyo discurso fue sometido a un análisis de contenido. Rodríguez, Gil y García (1999, p. 35) plantean que este tipo de investigación se caracteriza por el uso de técnicas que hacen factible recabar datos sobre la particularidad de las situaciones, posibilitando una descripción exhaustiva y densa de la realidad concreta objeto de investigación. Se aplicó un total de 15 entrevistas a profundidad, realizadas en un periodo de cuatro meses -de noviembre de 2014 a febrero de 2015-, a representantes de distintos sectores de la comunidad, tres personas de la tercera edad, ocho adultos y cuatro jóvenes, de los cuales siete son hombres y ocho mujeres, que han participado en la peregrinación en los diversos papeles que pueden desempeñarse, a fin de obtener diferentes puntos de vista e historias de vida en cuanto a la peregrinación se refiere.

Con el análisis de contenido fue posible realizar distintas interpretaciones de las expresiones que marcaron los entrevistados en sus acciones, lo cual proporcionó la información requerida para llevar a cabo el análisis subjetivo del comportamiento social de los peregrinos del pueblo de Tepexoyuca e identificar las concepciones, percepciones, valores y motivaciones con los que se construyó el 
- Fe, recreación y turismo: el peregrino del pueblo de Santa María de la Asunción Tepexoyuca,

ethos social. Para Lalive d'Epinay (1990, p. 40), el ethos social supone un principio de interpretación y de significación el cual se entiende por un conjunto de creencias, normas, valores y modelos que orientan un comportamiento.

\section{Modelo de interpretación}

El modelo de análisis de contenido que propone Lalive d’Epinay (1990, p. 40) se enfoca en "construir un modelo operativo a partir del concepto de ethos para estructurar el modelo teórico de análisis, este modelo se construye a través de un esquema en el que se definen las llaves de inter interpretación elegidas fueron el trayecto de vida, la religión y la peregrinación, como se explica a continuación.

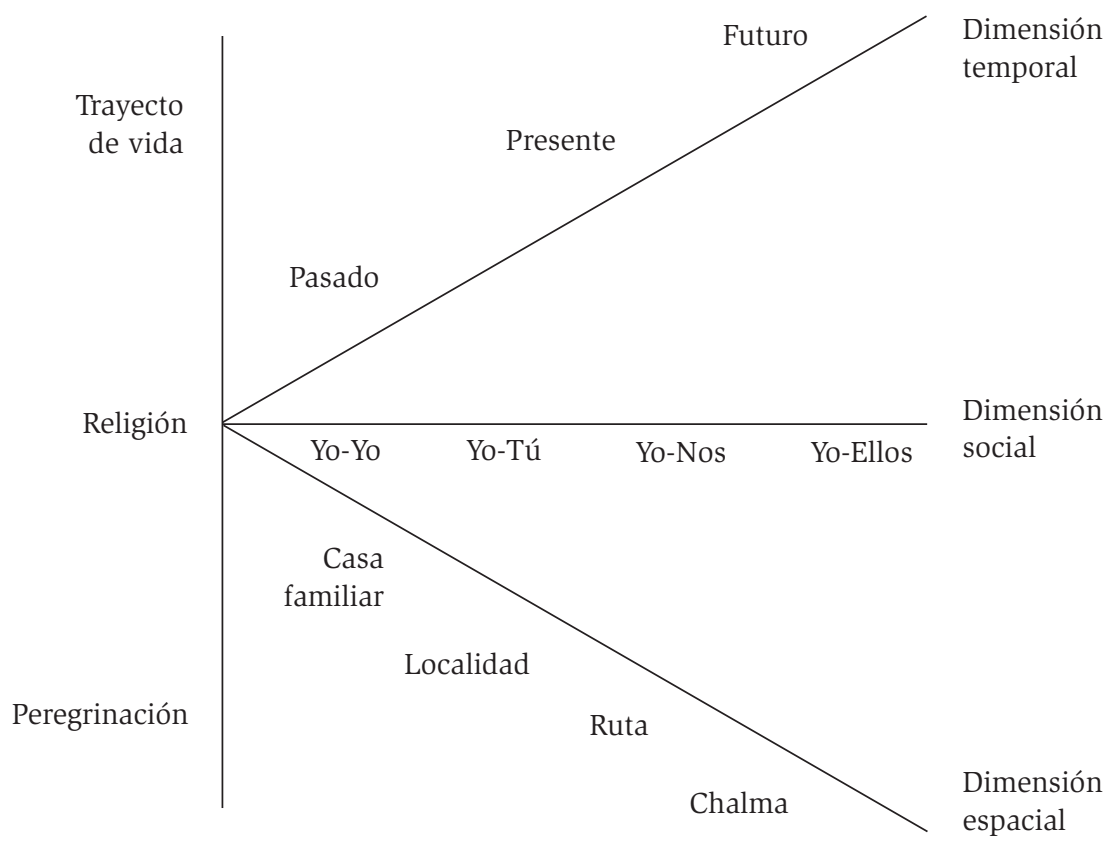

Fuente: elaboración propia 
La dimensión temporal marca una línea cronológica en el trayecto de vida del peregrino, analizando sus experiencias en el pasado, el presente y las expectativas en un futuro. En este análisis se obtuvo información de cómo ha sido la transición temporal en la vida del peregrino y en la misma peregrinación, y cómo es que las tradiciones que involucran a esta se han visto modificadas por la forma de pensar de participantes jóvenes.

En cuanto a la dimensión social y el cruce con la religión como llave de interpretación, el análisis se enfocó en los distintos tipos de relaciones existentes del peregrino. En un principio se indaga sobre la relación que tiene con sí mismo (Yo-Yo) y con su familia (Yo-Tú), para posteriormente estudiar la relación con la comunidad peregrina (Yo-Nos) y, por último, con la comunidad receptora de Chalma (Yo-Ellos).

La dimensión espacial permitió conocer la manera en que se desenvuelven las personas a lo largo de la peregrinación, enmarcando como espacios de análisis la casa familiar y la localidad -donde el peregrino se prepara-, la ruta que se sigue desde Santa María de la Asunción Tepexoyuca hasta el santuario del Señor de Chalma, y Chalma como el lugar de destino para la realización del ritual.

A continuación se presentan los resultados obtenidos del modelo de interpretación aplicado.

\section{Resultados de la investigación}

Análisis de las dimensiones del ethos de los peregrinos de Tepexoyuca Dimensión temporal

A lo largo del tiempo, la peregrinación se ha consolidado como parte de las costumbres del pueblo de Tepexoyuca, dejando una experiencia en el trayecto de vida del peregrino, el cual siempre hará referencia al pasado para afirmar la idea de por qué se sigue llevando a cabo la peregrinación y cómo es que se llega a formar parte de ella.

Sí, yo desde que me acuerdo, como le digo, tengo 80 años y yo desde que tenía cinco años, de ahí para acá, nunca he dejado de ir a Chalma, y la peregrinación ya estaba más años atrás, ya que se yo... muchísimo tiempo atrás, según mi papá me platicaba que desde antes de la Revolución ya estaba esa peregrinación. 
- Fe, recreación y turismo: el peregrino del pueblo de Santa María de la Asunción Tepexoyuca, Ocoyoacac, Estado de México

Si bien no existe una fecha en concreto de cuándo el pueblo de Tepexoyuca comenzó a ir en peregrinación al santuario del Señor de Chalma, las familias siempre han inculcado a sus hijos que continúen con la tradición; se observa como una etapa importante en el trayecto de vida de la persona, haciendo muchas referencias a lo que solía ser, cómo se fue desarrollando y lo que implicaba formar parte de la mayordomía del Señor de la Cañita, o ser solamente peregrino.

Yo he ido desde muy niña, la verdad mi familia me inculcó en venerar esta imagen, yo empecé ahí cuando mis abuelos eran mayordomos, fui acompañándolos como mayordomos, y ya pues por el cariño que le tomé a la imagen, me fui como copalera.

La vivencia del pasado en la vida de las personas fue la base que propició que siguieran con estas tradiciones hasta la actualidad, formando parte de la actividad de la misma manera que años atrás, participando como actores de la peregrinación.

Mi primera experiencia fue por mis papás, a mí me inició mi mamá con sus costumbres de ella, ella como más grande que yo, ya iba a Chalma, pero por un tiempo lo dejó, porque nosotros estábamos pequeños. Cuando pensó que ya estábamos en edad, no adecuada tal vez, pero que ya aguantábamos, nos llevó.

Hoy en día se identifican ciertos cambios de actitudes, por ejemplo, que ya no hay quien cargue la imagen por largas distancias; se menciona que los cargadores y peregrinos de antaño tenían más resistencia en cuanto al peso de la imagen, que es llevada en la espalda, lo cual se debía a la forma de vida de antes, cargando ollas de barro o costales de maíz de la cosecha, favoreciendo que las personas contaran con la fuerza y resistencia suficientes para trasladar la imagen por trayectos prolongados.

Yo te voy a decir una cosa, nunca me he aventado a cargar, me da miedo, yo nunca he tenido el valor para cargar. [...] Antes, yo me acuerdo. Un señor que se llama Martín Alva, aguantaba un buen tramo con la imagen, mi papá también, yo según me preparaba, pero nada más a la mera hora no, me daba miedo, aún me da miedo.

No obstante, aunque los jóvenes no logran recorrer mucha distancia con la imagen, los entrevistados resaltan que lo hacen con mucha devoción, ya que les nace cargarla y ponen todo su esfuerzo en ello. 
Las mayordomías, como organizadoras de la peregrinación, han ido cambiando a través del tiempo; actualmente las personas tienen distintas formas de pensar y puntos de vista en cuanto a sus tradiciones y a la peregrinación.

La mayordomía tiene costumbres muy arraigadas y vemos que hay muchas cosas en las que no coincidimos siempre, porque también esas tradiciones consideramos que ya son superfluas o no contribuyen [...] nosotros lo vemos así como una forma de contribuir a que esta tradición perdure.

Ser mayordomo en la peregrinación conlleva que la persona en un futuro sea respetada por haber servido a la imagen; un entrevistado comenta que esto es parte de su forma de vida, además de contribuir a preservar la manera en que se han ido transmitiendo esos buenos ejemplos por años, como normas que los han regido a través del tiempo y que siguen integrando sus tradiciones.

Durante el tiempo que he sido mayordomo, las tres o cuatro veces nos hemos ganado un respeto, no nos decimos "mira esto, mira lo otro", no. "Compadrito ¿cómo ha estado?", la imagen nos unió, como compadres, pero ahora ya la juventud no se tiene mucho respeto, pero gracias a Dios hemos tenido mucho respeto...

Al indagar sobre la perspectiva de futuro de la peregrinación, las personas reflexionaban sobre lo que ahora está pasando y cómo creen que continuará adelante su tradición.

Yo creo que con más desorden, si seguimos sin poner un alto o si seguimos sin seguir las reglas que nos han enseñado nuestros padres, pues si puede desaparecer o se va a agarrar a modo de relajo, ya no va a ser con la seriedad con la que se debe de ir.

Lo único que tal vez puede afectarla... los jóvenes o los mayordomos jóvenes que se han anotado, es que tal vez no son tan maduros y les está costando trabajo el compartir o saber escuchar a los que ya fueron mayordomos.

Cabe apuntar que con el paso de las generaciones el respeto es un valor que se ha visto transformado, pues ya no se conserva el mismo trato entre peregrinos y mayordomos.

Entre ellos no han tenido mucho respeto, pero no se pierde la tradición, hay personas que son o van a ser mayordomos muy jóvenes, pero van viendo, como van 
- Fe, recreación y turismo: el peregrino del pueblo de Santa María de la Asunción Tepexoyuca, Ocoyoacac, Estado de México

también caminando, y van viendo la organización del pueblo, se van dado cuenta que es una responsabilidad.

Dentro de esta dimensión es importante resaltar el lazo que existe en el pasado como el origen y desarrollo de esta tradición a la cual se aferran, ritual que en el presente buscan preservar como patrimonio intangible de la comunidad, transmitiendo principalmente los conocimientos adquiridos de la experiencia de haber participado a muy temprana edad.

Asimismo, destaca que pese a que existe esta transferencia de tradiciones, la transmisión generacional es frenada en ciertos casos, debido a que algunas familias se abstienen de continuar el pase de tradiciones, pues con el transcurso del tiempo se ha visto renuencia en formar parte del acto religioso, sea por cuestiones de fe, cambio de opiniones respecto a las manifestaciones religiosas 0 perdida de interés, lo cual alienta la incertidumbre de los peregrinos acerca de la realización de este ritual en el futuro.

\section{Dimensión social}

En este apartado se analiza la relación de los peregrinos de Tepexoyuca con sí mismos (Yo-Yo), con su familia (Yo-Tú), con la comunidad peregrina (Yo-Nos) y, por último, con los pobladores de Chalma como comunidad receptora (YoEllos).

En las relaciones Yo-Yo y Yo-Tú, los entrevistados expresan cómo se ha constituido en ellos el interés por formar parte de esta peregrinación, destacando que es a través de la familia que se fortalece la práctica religiosa.

¿Por qué voy? Pues simplemente... yo creo que sería porque esa peregrinación la tengo desde la infancia, como un legado por parte de la familia.

Yo voy porque así me lo enseñó mi papá y mi abuelito, ellos me enseñaron y yo quiero conservar esa tradición.

Los peregrinos 0, en su caso, los mayordomos siempre cuentan con el apoyo de la familia para cualquier cosa que necesiten, sin importar que ellos la hayan solicitado o sea voluntaria.

Alguien de la familia, sean los mismos hermanos, familiares o vecinos que dicen "mira, ten esto... llévate esto..." "No te preocupes, ustedes cumplan ahora sí que 
con agarrar el morral y la mayordoma su sahumerio. Váyanse, que nosotros nos encargamos".

La familia se establece como la base de la peregrinación, pues es el núcleo social en el que se inculca al peregrino formar parte de esta, dándole continuidad al ritual. Además se brinda el apoyo para que el peregrino y/o mayordomo concluya satisfactoriamente la peregrinación o compromiso, tomándolo como una responsabilidad familiar, no individual.

Hay muchas actividades donde la familia es soporte indispensable para realizar las actividades mismas, ya sea en algunas cosas que tienen que llevarse a lugares específicos, la preparación de la comida, hacer compras, llevar cosas al santuario, o incluso algunas veces te tienen que relevar en algunas reuniones que la mayordomía tenga y tú por tu trabajo no puedes asistir, pero sí es súper indispensable la familia, cuando tú aceptas la invitación incluso prácticamente estás llevando a la familia adelante, porque sin ella no sales con el compromiso.

En cuanto a la relación Yo-Nos, se observa el lazo que se configura entre los miembros de la comunidad peregrina, siendo la fe el principal motor para que ellos convivan y lleguen al santuario del Señor de Chalma, ya sea para dar gracias por la cosecha, por salud, o solo por devoción.

Lo que tiene también la gente es que se va comunicando más, vas echando un poquito de relajo sano, porque vas motivando a la señora a que camine, al señor... a lo mejor le pides un poco de agua, incluso conoces mejor hasta a tus vecinos, pero hay veces en las que pues sabes que son tus vecinos y punto, pero en ese momento, a lo mejor, por ejemplo si te caes, pues ellos acuden a ti, y ya te auxilian [...] vas tú compartiendo con la gente, animándote para que puedas llegar a Chalma.

Pero si tú le tienes fe al Señor de Chalma puedes ir y puedes pedirle por tus papás, ofrecerle el sacrificio de que vas caminando y siguiendo sus pasos, esa es la devoción que debes de llevar. Entonces, yo pienso que Dios verá, "Esta señorita viene en gracia de Dios, siguiéndome. Ahora voy a darle la oportunidad para que sus papás se compongan".

La religión juega un papel muy importante debido a que, gracias a ella, la comunidad se integra, ya sea como peregrinos o como mayordomos. Se menciona 
Fe, recreación y turismo: el peregrino del pueblo de Santa María de la Asunción Tepexoyuca, Ocoyoacac, Estado de México

que desde antes de que se lleve a cabo la peregrinación, los mayordomos se reúnen para establecer una hora de salida y las distintas ideas que puedan surgir sobre el desplazamiento.

El mayordomo mayor dice cómo nos organizamos, preparamos antes, que sé yo, unos dos o tres meses antes, qué es lo que se va a hacer, cómo nos vamos a organizar, a quién le van a tocar las asistencias en tal parte.

Los que a lo largo de la ruta observan y conviven con los peregrinos, así como la comunidad receptora en Chalma, permiten advertir la relación YoEllos, pues se analiza el modo en que las personas ajenas a la peregrinación aceptan y apoyan a quienes forman parte de este ritual.

Pasan a un lugar que se llama "la huerta", ahí según cuentan que tiempo atrás la imagen se quería quedar en una peregrinación, la querían levantar pero se hizo muy pesada, y el señor que vivía ahí oró a la imagen pidiéndole que se fuera con la gente que venía, desde ese entonces ya se tomó como descanso, los dueños de esa huerta ofrecen de comer, dan tacos de frijoles, de lo que tengan.

Existen personas de los lugares por donde vamos pasando que se organizan y ofrecen agua o un pequeño refrigerio para los peregrinos.

Los peregrinos conviven con las personas que año tras año los observan y animan a seguir caminando; regalan juguetes a las comunidades que no cuentan con recursos suficientes para brindar un obsequio por el Día de Reyes a los niños, viéndolo de cierta manera como una manda pagada a la imagen.

Algunos peregrinos o mayordomos se organizan y llevan dulces y juguetes y los van regalando durante el camino, y entonces los niños de Ahuatenco o el Arenal dicen que son los tres Reyes Magos, porque son las tres imágenes que van.

Llegando al destino, las personas de la comunidad aplauden y reciben a las imágenes y a quienes las acompañaron durante día y medio de recorrido; brindan comida, música y espacio donde descansen los peregrinos después de terminar el trayecto.

Ya los mayordomos se van a sus casas allá a donde las personas les rentan o permiten que se queden. A otro día pues los compadres ya sabemos que nos organizamos "compadre, por favor, queremos que en la primera misa estén todos, vamos a ver cómo está la imagen”. 
La convivencia con la comunidad de Chalma se expresa en su totalidad en la realización de la fiesta del 6 de enero, donde se reúnen peregrinos con locales en las comidas que ambos brindan, así como en la festividad en honor a las imágenes del Señor de la Cañita y el Cristo del santuario del Señor de Chalma.

El día 5 hacen el cambio de mayordomía que es cuando recibe la mayordomía de la imagen pequeña y el día 6 , los de la imagen grande. Otra obligación de los mayordomos es dar de comer a la gente que invitan, gente del pueblo de Tepexoyuca y gente de Chalma.

Así, las relaciones sociales que establecen los peregrinos con su entorno permiten definir cómo es que a partir de la relación con su familia se integran a la actividad, a la comunidad peregrina y a la del entorno, cuyos miembros fortalecen la expresión de fe y respeto a la imagen por la cual se efectúa el peregrinaje.

\section{Dimensión espacial}

La organización para el peregrinaje inicia en la casa, donde el peregrino junto con la familia realiza todos los preparativos para ir al santuario del Señor de Chalma.

Dos o tres días antes se iba a construir el jacal donde nos vamos a quedar en "el monte", se iba a cortar leña y a apartar el espacio en donde nos íbamos a quedar, ahora varios llevan casas de campaña, pero antes no, antes se hacían con palos y madera que encontrábamos allá. También salían camionetas de la casa con cobijas y las demás cosas que se necesitan en "el monte" y en las hospederías, cosas que no se pueden llevar caminando.

En la mañana antes de partir pasábamos a casa de los abuelos por su bendición, era de ley ir con el abuelo "denos su bendición, ya nos vamos".

Los mayordomos terminan de afinar detalles antes de irse, dejan instrucciones a la familia y se reúnen con los demás mayordomos para revisar que todo esté bien.

Nos ponemos de acuerdo para ver en dónde se va a dar la comida, o dónde se van a dejar las cosas que la camioneta lleva adelante, agradeces a las personas que van a llevar la comida, y te despides para ir con los demás mayordomos al oratorio y a la iglesia. 
- Fe, recreación y turismo: el peregrino del pueblo de Santa María de la Asunción Tepexoyuca, Ocoyoacac, Estado de México

Es en la comunidad donde se desarrollan los acuerdos para conformar el grupo que vaya a la cabeza de la peregrinación, así como para reunir a personas que puedan apoyarlos al dar de comer en los descansos; incluso el delegado, como responsable de la comunidad, forma parte importante de la peregrinación, pues él obtiene los permisos y apoyos para que sea llevada a cabo sin ningún percance y con todas las facilidades posibles durante la ruta.

La peregrinación busca no causar problemas a los automovilistas, debido a que parte del recorrido debe hacerse por carretera. Los entrevistados resaltan la capacidad de organización de los peregrinos y el buen comportamiento que tienen dada la magnitud del desplazamiento. Se menciona también la noche que pasan en "el monte”, donde descansan para poder partir el segundo día.

Cuando llegas al monte es muy bonito porque pues tus familiares u otra gente están esperando a la imagen y la van a encontrar, sale gente con veladoras, las mayordomas van con sus ceras para alumbrar el camino.

Ahí, los peregrinos y mayordomos conviven durante la noche, ya que se quedan velando la imagen, con violinistas, música de banda e incluso arrieros bailando afuera de donde se encuentran las imágenes del Señor de la Cañita.

Durante el trayecto de la peregrinación, comentan los entrevistados, se observan los distintos motivos por los que van formando parte de ese acto.

Es parte de cada persona, no creo que nada más sea de unos cuantos. Para todos es de ley, cada año, te inviten o no te inviten, tengas a donde llegar o no, tienes que ir, es una tradición que nos inculcaron y por respeto o por amor a la imagen, por favores o lo que sea, se tiene que ir año con año, ya es muy importante.

Luego simplemente te invitan entre familia, primos, antes era más de "¿Qué, vamos a ir a Chalma?", y pues sí ibas, y al siguiente año también.

No le tomas la idea central de ir a Chalma, tú lo veías como el irse a las albercas, a bañar.

Se menciona que, durante todo el recorrido, la comunidad va rezando, agradeciéndole a la imagen, y cómo cada mayordomo les ofrece alimento a los peregrinos.

Pues los violines van todo el camino desde que salen de Tepe hasta Chalma, todos los violines van tocando, a lo mejor no se saben las notas ni nada de eso, pero es 
música que te alegra el camino, y los rezanderos pues van alabando todo el camino a la imagen con cantos, entonces es muy bonito porque van escuchando a los violines, a los rezanderos.

En el santuario del Señor de Chalma, los peregrinos ven reflejada su fe y esfuerzo puestos a lo largo de la peregrinación, además de considerarlo como un segundo hogar para el Señor de la Cañita e incluso para ellos mismos; también lo conciben como un espacio donde continuar su ritual hasta que se cumpla el plazo para regresar a su comunidad. Durante la estadía en Chalma, se ofrecen "asistencias" por parte de cada uno de los mayordomos que recibirán el cargo el año siguiente; los peregrinos acuden a estas para convivir y formar parte de los preparativos para la fiesta grande del 6 de enero, donde se hace el cambio de juramento en una misa que ha sido pagada para el evento.

Las mañanitas a las cuatro de la mañana, a las seis es la misa y después se va uno con el mayordomo, a la cuenta de limosna que se juntó de aquí hasta allá, se cuenta. Después se va a desayunar con el mayordomo. En la noche la cena, castillos y la variedad. La mayordomía solo lleva a los arrieros, también se van de aquí y bailan allá.

Dentro del ritual del peregrinaje se abre paso un espacio para la recreación de los peregrinos, ya sea para festejar que llegaron bien al templo sin ningún percance o retraso, o al concluir las actividades propias del ritual.

Nos levantaban a las seis de la mañana para ir a misa, y sí íbamos, ya después nos entreteníamos un ratito y nos íbamos a desayunar, "ya vinimos, mamá”, ya nos daban de desayunar y nos desaparecíamos todo el día a las albercas. Ya regresábamos a la hora de comer y nos íbamos a casa del mayordomo, ya después en la tardenoche salíamos a pasear, yo a Chalma lo conocía de arriba abajo.

La introducción de actividades ajenas al ritual religioso evidencia que la recreación es una práctica que sí se realiza, aunque no es bien vista.

Yo me acuerdo que una ocasión, por primera vez dijeron "párense, ya pusieron un columpio", pero fue raro, porque unos decían "cómo voy a creer, vienen a jugar, a divertirse, si venimos en peregrinación”. Fíjate nada más cómo hay gente que viene cambiando eso, que ya no llevan el mismo fervor o devoción de ir, porque así, Dios no te lo agradece. 
- Fe, recreación y turismo: el peregrino del pueblo de Santa María de la Asunción Tepexoyuca, Ocoyoacac, Estado de México

Con los mayordomos son unas pachangas, los que van a dejar el cargo se ponen a bailar con las comadritas, con el violín y todo, a bailar porque ya pasan a ser los viejitos. Hasta bailecito hay. ¿Y qué no dicen que ese es un lugar para reflexionar? A mi compadre por eso lo criticaron, porque se quejó de eso y no lo hizo, su esposa me decía que entre comadres se avientan al agua y están tomando y bailando.

Lo anterior permite observar, al menos, dos tipos de peregrinos: aquellos que eluden la recreación durante la peregrinación y censuran a quienes la practican, y aquellos que la enlazan con los rituales de la peregrinación y para quienes no existe una contraposición entre ambas cosas. Esta distinción se asume como fundamental para reconocer que no hay un solo tipo de ethos del peregrino de Tepexoyuca, sino que su configuración se bifurca en distintos valores, creencias y comportamientos.

\section{Caracterización del ethos}

De acuerdo con los valores identificados en los peregrinos, se reconocen dos tipos de ethos, denominados inflexible y flexible, dada la actitud de las personas ante la práctica religiosa y su conjugación con la recreativa, además de otros aspectos de innovación a la tradición. Se describen a continuación los elementos distintivos de cada uno.

\section{El peregrino inflexible}

a) Devoción al Señor de la Cañita. Se señala un gran apego a esta representación por haber otorgado múltiples milagros a los fieles de la comunidad, quienes deciden "acompañar sus pasos" durante la peregrinación, o "servirle" como mayordomos; a partir de esta imagen se establecen los lazos en la comunidad. La devoción de los peregrinos en la imagen del Señor de la Cañita genera también un compromiso con ella para expresar su fe durante el recorrido, pues esta devoción motiva a que el peregrino se arrepienta de sus pecados, cumpla una manda, haga un juramento o simplemente "siga los pasos del Señor de la Cañita" por el cariño hacia la imagen.

b) Identidad con la comunidad. El acto religioso se ha instituido como una expresión de la identidad del pueblo, ya que una gran mayoría de personas participan y lo promueven como parte de su cultura, pues la imagen 
también integra el patrimonio del pueblo de Santa María de la Asunción Tepexoyuca.

c) Tradición. Se enmarca el interés por conservar costumbres que fueron establecidas en familia por antepasados, ya que la manera en que fue transmitida esta práctica ha fortalecido su carácter tradicional, así como el de los rituales previos y posteriores de peregrinos y mayordomos.

d) Respeto. El respeto se asume como esencial, lo principal para realizar esta manifestación, respetando principalmente la imagen y la sabiduría de las personas mayores, quienes guían a las nuevas generaciones sobre cómo llevar a cabo este peregrinaje. El respeto también está presente en el trato a los acompañantes, sea en mayordomía, comunidad o con los peregrinos, y con el mismo culto religioso.

\section{El peregrino flexible}

a) Reconocimiento social. El interés por establecer una posición ante la comunidad como una persona que ha cumplido con llegar al santuario del Señor de Chalma en calidad de peregrino, que ha participado como mayordomo de la imagen, y que ha brindado grandes cantidades de comida, promueve un fortalecimiento del ego. Este peregrino (sea o no mayordomo) busca cumplir con una invitación, sea a manera de compañía durante el recorrido, o como algún apoyo o asistencia en la peregrinación. La realización de este ritual no es consecutiva, pues no representa algo primordial en su práctica religiosa.

b) Innovación en la ritualidad. Refiere distintos puntos de vista sobre la manera de llevar a cabo la peregrinación y los rituales que la constituyen, lo que ocasiona que se difiera sobre los actos de las tradiciones ya establecidas. Se destaca también que el núcleo familiar de este perfil contribuye a la generación de nuevas ideas para modificar las costumbres, originando incertidumbre en torno al futuro de estas.

c) Recreación. El peregrinaje incluye dentro del ritual religioso la posibilidad de ir conociendo distintos lugares a lo largo de la ruta. Parte de la motivación de este tipo de peregrinos por emprender el camino al santuario del Señor de Chalma se enfoca en que, posteriormente a la llegada al templo, se disfrutará de los balnearios y del consumo de dulces 
- Fe, recreación y turismo: el peregrino del pueblo de Santa María de la Asunción Tepexoyuca,

típicos y artesanías que el destino ofrece, sin dejar a un lado la posibilidad de comer sin costo en las asistencias de los mayordomos durante la estadía en Chalma.

\section{Conclusiones}

El presente caso de estudio ha brindado como resultado la distinción de dos perfiles de peregrinos, donde los valores detectados permiten observar, por una parte, al peregrino inflexible como aquel que tiene prioritariamente un compromiso con su fe, y pone su cariño y devoción en la imagen del Señor de la Cañita como principal motor para formar parte de este desplazamiento, destacando el interés por preservar la tradición y las formas aprendidas que los identifica como la comunidad de Santa María de la Asunción Tepexoyuca.

Por otra parte, el peregrino flexible se reconoce como aquel cuyas motivaciones son distintas, dejando a un lado los estereotipos de un peregrino ortodoxo, combinando el ritual con la recreación y la convivencia, modificando el formato tradicional y estableciendo un compromiso con la comunidad, familia y amigos, buscando distinguir su posición ante la comunidad. Este peregrino no marca la necesidad de ir año tras año a la peregrinación, suele recurrir a ella cuando es invitado a formar parte del desplazamiento, donde manifiesta su deseo de recreación y uso de tiempo libre.

La identificación de estos perfiles permite concluir que, si bien la práctica religiosa de los peregrinos de la comunidad de Tepexoyuca se enmarca en un turismo religioso y que el perfil del ethos inflexible aún es dominante, la aparición de un ethos flexible de peregrino como manifestación reciente conduce a pensar en la introducción de un cambio en la práctica cultural de la población, la cual se acerca más a una expresión de la sociedad actual posmoderna, ligada a los valores de la imagen, el consumo y la recreación. 


\section{Fuentes consultadas}

Aulet, S. y Hakobyan, K. (2011). Turismo religioso y espacios sagrados: una propuesta para los santuarios de Catalunya. Revista Iberoamericana de Turismo, 1(1), 63-82. Recuperado de http://dugi-doc.udg.edu/bitstream/ handle/10256/9123/TurismoReligioso.pdf [2015, 17 de abril].

Cànoves, G. y Blanco, A. (2011). Turismo religioso en España: ¿la gallina de los huevos de oro? Una vieja tradición, versus un turismo emergente. Cuadernos de Turismo, 27, 115-131. Recuperado de http://revistas.um.es/ turismo/article/view/139791 [2015, 16 de abril].

Crespi, F. (1997). Acontecimiento y estructura: Por una teoría del cambio social. Buenos Aires: Ediciones Nueva Visión.

Fernández, A. M. (2010). El Santo Niño de Atocha: patrimonio y turismo religioso. PASOS. Revista de Turismo y Patrimonio Cultural, 8(2), 375-387. Recuperado de http://www.redalyc.org/articulo.oa?id $=88112768010$ [2015, 13 de abril].

Instituto Nacional de Estadística y Geografía (2010). Ocoyoacac. Recuperado de http://www3.inegi.org.mx/sistemas/Movil/MexicoCifras/mexicoCifras.aspx?em $=15062 \& \mathrm{i}=\mathrm{e}[2015,20$ de marzo $]$.

Iracheta, M. y Montes, O. (2009). Dos celebraciones religiosas en un mundo globalizado. Revista de Ciencias Sociales, XV(1), 34-49. Recuperado de http://www.redalyc.org/articulo.oa?id=28011674004 [2015, 17 de abril].

Juárez, J. et al. (2012). Peregrinación y turismo religioso en los Santuarios de México. Geografía de Valparaíso, 46, 41-53.

Lalive d'Epinay, C. (1990). Récit de vie, ethos et comportament: pour une exéngése sociologique. En J. Remy y D. Ruquoy (dirs.), Méthodes d' analyses de contenu et sociologie (pp. 37-68). Bruselas: Publications des Facultés Universitaires Saint-Louis (col. Socioligie).

Martínez, R. (2009). Un acercamiento al turismo religioso en los Altos de Jalisco. ORBIS. Revista Científica Electrónica de Ciencias Humanas, 13(5), 47-66. Recuperado de http://www.redalyc.org/articulo. oa?id $=70911922005$ [2015, 13 de abril $]$.

Millán, V. et al. (2010). Turismo religioso: estudio del camino de Santiago. Gestión Turística, 13, 9-37. 
- Fe, recreación y turismo: el peregrino del pueblo de Santa María de la Asunción Tepexoyuca, Ocoyoacac, Estado de México

Rebic, A. (1999). Documento de la Santa Sede sobre el Peregrinaje del 2000. Recuperado de http://www.medjugorje.hr/es/fenomeno-de-medjugorje/encuentros-internacionales/conferencias/neum1999\#adalbert-rebic [2015, 13 de abril].

Ritzer, G. (1993). Teoría sociológica contemporánea. México: McGraw-Hill.

Rodríguez, G., Gil, J. y García, E. (1999). Metodología de la investigación cualitativa. Málaga: Aljibe.

Ruezga, G. y Martínez, R. (2011). El turismo por motivación religiosa en México: el caso de San Juan de los Lagos. Recuperado de http://issuu.com/ rogeliomartinez9/docs/libro_turismo_espiritual [2015, 15 de abril].

Schütz, A. (1995). El problema de la realidad social. Buenos Aires: Amorrortu. Sharpley, R. (2009). Tourism, Religion and Spirituality. En Tourism Studies. Handbook (pp. 237-253). Great Britain: Sage. 